\title{
Commentary
}

\section{Beyond Melamine: More Reasons Not to Use Animal Milk in Infant Feeding}

\author{
Ted Greiner, PhD
}

The widespread panic caused by the discovery that melamine was commonly added to milk in China was justified. Treatment of the resulting renal damage has been challenging, and the causal mechanism is unknown. But the underlying cause of this phenomenon is receiving little attention. Wherever quality control procedures are inadequate, milk can be and probably often is sold with unknown amounts of water added to increase profits of either dairy farmers or middlemen, or both. If it is challenging for large infant formula manufacturers to prevent dilution or other adulteration of the milk they buy, then animal milk, still more widely used as a breast milk substitute than infant formula in low-income countries, should be more widely acknowledged as dangerous for infant feeding. Meanwhile, governments around the world continue to undervalue breastfeeding and fail to take the steps needed to protect, support, and promote it.

\section{Commentary}

Improperly manufactured infant formula is again generating media attention, this time in China. Infant formula recalls are apparently relatively common. ${ }^{1}$ It is

Received for review December 5, 2008; revised manuscript accepted for publication June 15, 2009.

The author declares no competing interests.

Ted Greiner is a professor of nutrition in the Department of Nutrition, College of Human Ecology, Hanyang University, Seoul, South Korea. He was previously a senior nutritionist at PATH for 4 years and for 19 years worked at Uppsala University Medical in Sweden, where he was an associate professor of international child health. He is on the professional advisory board of ILCA, the International Advisor Committee of the World Alliance for Breastfeeding Action, and is currently the elected chair, $\mathrm{NGO}$ / CSO Constituency, United Nations Standing Committee on Nutrition.

Address correspondence to Ted Greiner, $\mathrm{PhD}$, Food and Nutrition Department, Hanyang University, 17 Haengdang-dong, Seongdong-gu, Seoul Korea 133-791; e-mail: tedgreiner@yahoo.com or tgreiner@hanyang.ac.kr.

J Hum Lact XX(X), XXXX

DOI: $10.1177 / 0890334409342404$

(C) Copyright 2009 International Lactation Consultant Association important that such careful watch is kept over this product, since it is one of the few single food items on which many human beings are completely dependent.

The underlying cause of the problem in China has wider implications, which have also received little attention. Melamine, $\mathrm{C}_{3} \mathrm{H}_{6} \mathrm{~N}_{6}$ (1,3,5-triazine-2,4,6triaminea), is a low-cost source of nitrogen $(66 \%$ by weight), commonly used in plastics, that is almost completely nontoxic on its own. Not incorporated into protein or amino acids in the body, it does not belong in food; however, it was illegally added to pet food and now milk in China to make these products look like they were higher in protein than they are. This tactic works when Kjeldahl or Dumas tests are used to estimate protein levels because they measure only the nitrogen content.

When melamine is added to pet food along with cyanuric acid, they jointly form crystals in the distal renal tubules, which leads to uremia and death. ${ }^{2}$ It is not known whether cyanuric acid was deliberately added or was a by-product of the added melamine. ${ }^{3}$ (It can be produced by hydrolysis of melamine. ${ }^{4}$ ) By December 2008, tainted infant formula had led to the deaths of 6 infants and 294,000 hospitalizations in China. ${ }^{5}$ In humans, the exact causal mechanisms for the renal damage that occurred on an unprecedented scale in China are uncertain, and clinical treatment is clearly challenging. ${ }^{6}$

In both China and here in Korea (where milk products commonly used to be purchased from China), there are anecdotal reports of increasing breastfeeding rates. But unless the underlying causes of the rapid decline in breastfeeding that had occurred in recent decades are addressed, one suspects that any recent improvement is likely to be temporary.

Behind this tragedy, a larger one goes unnoticed year after year. Wherever those who purchase milk do not maintain sufficiently careful quality control, milk producers or middlemen can make more money by diluting their product with water. Until it is extreme, 
this practice is not detectable by the purchaser. In some countries, milk is apparently often diluted more than once in trade (personal communication, Viveka Persson). ${ }^{7}$ Mothers also commonly dilute the animal milk they give to their children, both to "stretch" it (that is, overdilute it to reduce the cost of feeding the child) and to make it better tolerated. (For younger infants, for whom cow milk is no longer commonly recommended, a certain amount of dilution is a necessary part of the required home preparation.)

Infant formula manufacturers are one of the few purchasers who actually test the milk to determine how dilute it is when they purchase it. Since testing for nitrogen is much cheaper than testing for protein, it has turned into a simple indicator for the level of dilution of the milk, opening the door for this particular scam. In India, dairies apparently test the freezing point of the milk to detect dilution, ${ }^{8}$ but this test also could be easily circumvented.

In low-income settings, animal milks are still more widely used in infant feeding than infant formula because of their lower cost and wider availability. Using the Stat Compiler, ${ }^{9}$ it is possible to create a table comparing use of "other milk" and infant formula for infants under 9 months of age for every demographic and health survey. Looking only at the most recent survey for each country and only at those that collected data simultaneously on both indicators $(\mathrm{N}=53)$, "other milks" were clearly fed more than infant formula to 7- to 9-month-old children in 41 countries and formula in 12. Because this tended to be the case in countries where cows are common (South Asia, East Africa) and not the case where cows are rare (eg, West Africa and parts of Southeast Asia), it is reasonable to assume that fluid animal milk was responsible for much if not most of this "other milk."

The World Health Organization has recently reversed its guidance on the use of home-modified animal milk as a breast milk substitute for HIV-infected infants because a review showed that it is too difficult to make properly in the home and too difficult and expensive to supplement adequately with missing micronutrients. ${ }^{10}$ Although this conclusion may be controversial, it still only considered mistakes made in diluting the milk in the home and did not address the larger issue discussed here - in some settings the only way to be completely sure that milk that enters the home is undiluted is to milk the animal oneself.

Animal milk is important for nutrition, especially of young children, and is crucial for those who do not receive adequate amounts of breast milk. Because of its high renal solute load (basically its high concentrations of minerals and protein), it must be diluted properly, based on the specific source, particularly if fed to younger infants in hot or dry climates. ${ }^{11,12}$ Dilution beyond what is needed will achieve fewer nutritional objectives, and indeed may seriously harm younger infants or older children for whom it is a large part of the diet. For others, overdiluted milk will perhaps not be harmful, simply serving as a source of overpriced water as well as whatever nutrients remain.

But this issue reminds us - and our governmentsthat replacing breastfeeding and human milk is, at some level, always a somewhat dangerous practice. Sadly, other problems linked to not breastfeeding get little or no attention. For example, in emergencies from China to New Orleans, non-breastfed infants are by far the group at highest risk of harm or death from interruption in food availability, something rarely recognized by emergency responders and almost never documented (see the Emergency Nutrition Network Web site for access to their excellent teaching modules on infant feeding in emergencies). ${ }^{13}$

Like cesarian section, artificial feeding should be something for which humankind pats itself on the back, as it can save lives. The issue is the overuse and misuse, resulting in unnecessary ill health, suffering, and death. Governments in much of the world should be ashamed that they do so little to provide the protection, support, and promotion breastfeeding needs to ensure that artificial feeding becomes the rare, "emergency" practice it was developed to be.

\section{References}

1. http://www.ibfan.org/site2005/abm/paginas/articles/arch_art/85-24. pdf. Accessed February 10, 2009.

2. Brown CA, Jeong KS, Poppenga RH, et al. Outbreaks of renal failure associated with melamine and cyanuric acid in dogs and cats in 2004 and 2007. J Vet Diagn Invest. 2007;19:525-531.

3. World Health Organization. Melamine and Cyanuric Acid: Toxicity, Preliminary Risk Assessment and Guidance on Levels in Food. Updated October 30, 2008. Available at: http://www.who.int/foodsafety/ fs_management/Melamine.pdf. Accessed February 10, 2009.

4. http://en.wikipedia.org/wiki/Cyanuric_acid. Accessed February 10, 2009.

5. China Bystander, December 2, 2008. Available at: http://chinabystander .wordpress.com/2008/12/02/death-toll-from-tainted-baby-formulaofficially-raised-to-six/. Accessed April 11, 2009.

6. Wong SN, Chiu MC. The scare of melamine tainted milk products. $H K$ $J$ Paediatr (new series). 2008;13:230-234.

7. Persson V, Greiner T, Bhagwat IP, Gebre-Medhin M. The Helen Keller International Food Frequency Method may underestimate vitamin A intake where milk is a normal part of the young child diet. Ecol Food Nutr. 1999;38:57-69. 
8. http://dairy.maharashtra.gov.in/index.php?page=quality-control. Accessed February 10, 2009.

9. http://www.statcompiler.com/index.cfm. Accessed February 10, 2009.

10. Briend A. Discussion Paper Prepared for HIV and Infant Feeding Technical Consultation, October 25-27, 2006. Home-modified animal milk for replacement feeding: is it feasible and safe? Available at: http://whqlibdoc.who.int/hq/2006/a91064.pdf. Accessed October 6, 2008.
11. Almroth SG. Water requirements of breast-fed infants in a hot climate. Am J Clin Nutr. 1978;31:1154-1157.

12. Dewey KG, Cohen RJ, Rollins NC; Informal Working Group on Feeding of Non-breastfed Children. WHO technical background paper: feeding of non-breastfed children from 6 to 24 months of age in developing countries. Food Nutr Bull. 2004;25:377-402.

13. Emergency Nutrition Network Web site. Available at: http://www .ennonline.net/. Accessed April 14, 2009. 